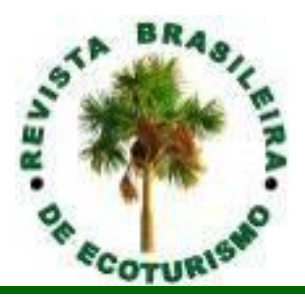

\title{
Contribuições do Agroturismo e Lazer para o Desenvolvimento Rural Sustentável
}

\section{Contributions of Agritourism and recreation for Sustainable Rural Development}

Cristiano Luis Metzner, Alvori Alhert

RESUMO: Atualmente as propriedades rurais podem não ser caracterizadas exclusivamente como produtores agropecuários. Outras atividades têm sido inseridas neste espaço, juntamente com as atividades tradicionais, com a finalidade de agregar renda às famílias e ao mesmo tempo contribuir para o desenvolvimento rural dentro de suas realidades. Este estudo teve como objetivo pesquisar o agroturismo e lazer em propriedades rurais de Marechal Cândido Rondon - PR, e discutir sua relação com o desenvolvimento rural sustentável, identificando os projetos existentes e analisando suas contribuições. A metodologia de pesquisa utilizada foi de natureza qualitativa/descritiva, com uma amostra não probabilística para representar a população a ser estudada, utilizando-se de entrevista com formulário para instrumento na coleta dos dados, e análise descritiva. Como resultado deste estudo identificamos cinco propriedades rurais que realizam projetos de agroturismo e lazer, que são: "Sítio das Orquídeas", "Pesque Pague do Alli", "Pesque Pague Paulista", "Cachoeira da Onça" e "Ricas Trilhas Verdes". Todas com mais de 10 anos de atuação em projetos de agroturismo. A maioria conta também com produções agrícolas tradicionais, sendo o agroturismo e lazer a atividade de maior renda da propriedade no momento. O valor de renda agregado aos lucros da produção tradicional trouxe melhores condições à estrutura física e social na propriedade, como também geração de novos empregos. Outra contribuição dos projetos é a continuidade dos filhos na propriedade, que, mesmo saindo para estudos, retornam para ajudar, auxiliando nas atividades. As transformações e cuidados com o meio ambiente foram aumentados devido a projetos de agroturismo e lazer terem sido incorporados nas propriedades, ampliando essa ideia também para os visitantes através de programas de educação ambiental, mesmo que modestos na maioria dos empreendimentos. Apesar de haverem poucos recursos por parte governamental, os investimentos privados seguem, mantendo os projetos em ação, mostrando o gosto que os produtores têm em mantê-los, sendo eles, também beneficiados no seu convívio social com os visitantes. Conclui-se que dentro de uma perspectiva de desenvolvimento rural sustentável, as propriedades estudadas estão desenvolvendo alternativas de trabalho, além das tradicionais do campo, com as quais estão se beneficiando e também oferecendo mudanças para a vida das pessoas que lá trabalham ou visitam, com altos ganhos também para o meio ambiente.

PALAVRAS-CHAVE: Agroturismo; Lazer; Sustentabilidade. 


\section{ABSTRACT}

Currently the rural properties are not caracterized mainly as agricultural producers. Other activities have been introduced, along with the traditional activities, with the purpose of aggregating better financial sources to the families and at the same time contributing to the rural development in their realities. This study has the objective of researching the agroturism and leisure in rural properties in Marechal Cândido Rondon - PR, and discuss their relationship with the sustainable rural development, identifying the existent projects and analyzing their contributions. The research methodology used was qualitative/descriptive, with a non probabilistic sample to represent the population to be studied, using a form interview as a collecting data instrument, and also descriptive analysis. As a result of this study we have identified five rural properties that perform agroturism and leisure projects and they are: Sítio das Orquídias, Pesque Pague Alli, Pesque Pague Paulista, Cachoeira da Onça and Ricas Trilhas Verdes. All of them more than 10 years operating these projects, most of them also have traditional rural production, but being the agroturism the most profitable income. This income agreggated to the traditional production profit brought better strutuctural and social conditions to the properties, generating more jobs.Another contribution of these projects is the permanence of the children in the property, supporting the activities, and even if going out to study, coming back to help out. The transformations and care with the environment were increased due to the incorporation of the agroturism and leisure projects in the properties, enlarging this idea to the visitors through ambiental education projects, despite lowly in the majority of the farms. In spite of the low governmental financial sources, the private investments are still going on, mantaining the projects in action, and the producers happy to mantain them, and also being these producers presentee in their social relationship with the visitors. At last, we conclude that inside a sustainable rural development perspective, the studied rural properties are developing new work alternatives, beyond the traditional farm ones, with what they are getting benefits and also offering changes to the lifes of the people who work or visit the place, with high gain to the enviroment too.

KEYWORDS: Agroturism; Leisure; Sustainable.

\section{Introdução}

É fato nos dias atuais o desenvolvimento de diferentes atividades econômicas nos espaços rurais. Além de manter suas atividades tradicionais de produção agrícola, pecuária e outras, as propriedades estão inserindo atividades não-agrícolas em sua estrutura. $O$ meio rural brasileiro vem registrando um aumento de atividades não agrícolas que até pouco tempo eram consideradas marginais, devido a pequena importância na geração de renda. Dentre essas pode-se destacar o Turismo Rural (Agroturismo) como uma atividade indutora do crescimento de ocupações não agrícolas no meio rural (SCHNEIDER; FIALHO, 2000).

Trata-se de um cenário onde o tema ruralidade busca a compreensão da relação entre o rural e o urbano, estabelecendo a diminuição de atividades agrícolas tradicionais e o aumento da busca de outras atividades (pluriatividade), por meio do engajamento em atividades econômicas múltiplas (ABRAMOVAY, 2001). 
Por isso, no contexto do Desenvolvimento Rural Sustentável, analisouse o tema do Agroturismo e do Lazer e suas características e potencialidades como experiências em desenvolvimento no município de Marechal Cândido Rondon - PR. O turismo rural constitui-se de uma atividade que une a exploração econômica a outras funções como a valorização do ambiente rural e da cultura local que, não raras vezes, são alguns de seus atrativos principais. Desta maneira, o turismo rural consiste em atividades de lazer realizadas neste ambiente rural (SILVA, 1999).

Quando discute-se ambiente rural também relaciona-se os aspectos ligados a natureza de forma geral, que também fazem parte do cenário rural e que juntos (ambiente rural, lazer, natureza, agroturismo, desenvolvimento sustentável) apresentam contribuições sobre a perspectiva da qualidade dessa interação do homem com a natureza, resultando em educação ambiental e a mudança de valores e atitudes (SCHWARTZ, 2006).

Propriedades em diferentes regiões do Brasil utilizam o agroturismo como opção de renda e, consequentemente, atingi outros objetivos incluindo a valorização do espaço rural e a sustentabilidade (GUZZATTI, 2003; LIMA; SOUZA; MATTOS, 2013).

O número de estabelecimentos que utilizam o agroturismo vem crescendo no Brasil nos últimos anos, demonstrando sua importância como opção de desenvolvimento rural (SILVA, 1999). Contudo, em vista do número de propriedades rurais com características da agricultura familiar e as mudanças que vem ocorrendo e do grande potencial das belezas naturais que o município de Marechal Cândido Rondon e toda região do Oeste do Paraná oferecem é que se justifica o presente trabalho.

A pesquisa teve como objetivo central investigar as propriedades e os projetos que realizam atividades de agroturismo e lazer no município de Marechal Cândido Rondon - PR. Na metodologia, o trabalho utiliza o método dialético/fenomenológico e o tipo de pesquisa qualitativa/descritiva. Através de entrevista junto às pessoas é realizado o preenchimento de um formulário.

\section{Desenvolvimento Rural Sustentável}

O Relatório Brundtland (1987), conhecido no Brasil como "Nosso Futuro Comum", publicado como texto preparatório à Conferência das Nações Unidas sobre Meio Ambiente (Eco - 92), a ideia de desenvolvimento sustentável aparece com o desafio de ser capaz de garantir as necessidades das gerações futuras, como apresenta Almeida:

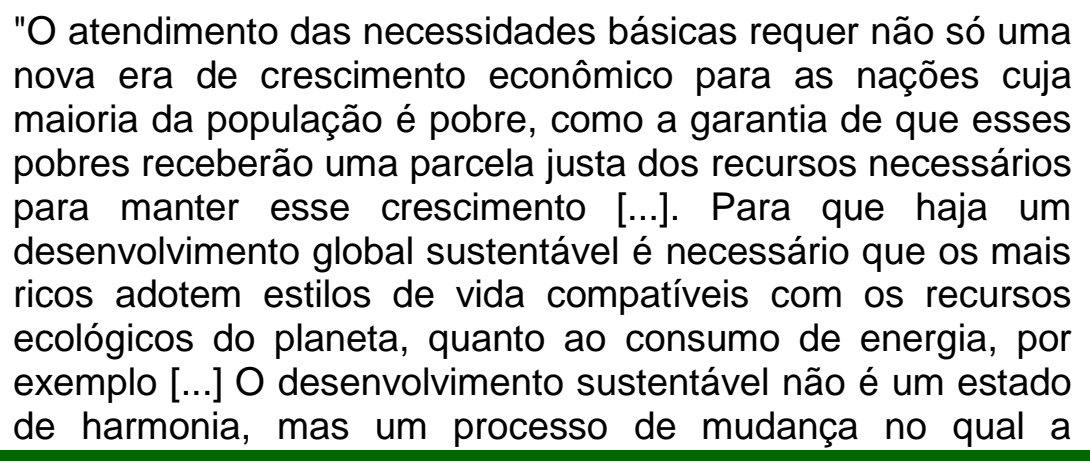


exploração dos recursos, a orientação dos investimentos, os rumos do desenvolvimento tecnológico e a mudança institucional estão de acordo com as necessidades atuais $\mathrm{e}$ futuras". (ALMEIDA, 1997, p. 42)

O desenvolvimento que vinha ocorrendo nas décadas de 1950 a 1990 orientava para o crescimento econômico, permanente, e baseado no consumo abusivo de recursos naturais como condição para que as sociedades tidas como "subdesenvolvidas" superassem o "atraso" e alcançassem o "progresso". É necessário partir do entendimento de que o desenvolvimento em sua formulação mais ampla seria a realização das potencialidades sociais, culturais e econômicas da sociedade, em sintonia com o meio ambiente que o rodeia e com seus valores políticos e éticos (COSTABEBER; CAPORAL, 2013).

Diante dessas novas compreensões, objetivando um futuro mais sustentável na economia, no setor social, cultural e ambiental, o meio rural está diretamente envolvido dentro desse processo.

Entende-se que "desenvolvimento rural" deve ser o resultado de uma série de transformações tanto qualitativas quanto quantitativas que se produzem no meio rural, e na qual os efeitos convergentes produzem, com o tempo, uma elevação do nível de vida e uma evolução a favor do gênero de vida. Ou seja, o desenvolvimento implica, ao mesmo tempo, um progresso econômico que se apoia no progresso técnico, e um progresso das pessoas, das comunidades, das regiões e das nações (BORDENAVE, 1988).

Vários problemas, entretanto, ocorreram neste período no que tange à desigualdade social e especialmente à sustentabilidade (econômica e ecológica) da produção agrícola no longo prazo.

Especialmente no plano econômico, tem-se a destacar, aliado à elevação expressiva de rendimentos ou de produtividade de alguns cultivos/atividades um encarecimento da utilização de insumos e a queda dos preços recebidos pelos agricultores. (ALMEIDA, 1997; p.44).

Neste ambiente de incertezas, foi na década de 80 que essa nova forma de pensar o desenvolvimento rural surgiu e, entre as diferentes visões, como estratégia do desenvolvimento agrícola sustentável, tem como foco principal neutralizar ou minimizar os efeitos das perturbações do homem no meio ambiente (ALMEIDA, 1997).

\section{Agroturismo: Origens, Conceitos e Desenvolvimento}

No meio rural, ao redor do planeta, em algum momento, as atividades de agroturismo, turismo rural, foram inseridas no ambiente da agricultura.

Apesar de ter um crescimento concentrado na Europa e nos Estados Unidos a partir da década de 1960, o turismo ganhou força na discussão sobre desenvolvimento rural em vários países somente no início da década 
de 1990, período em que cresceu o fenômeno da pluriatividade no espaço rural juntamente com a concepção de multifuncionalidade do agricultor e da agricultura, bem como o interesse dos agentes turísticos e da população urbana pelo rural e pelas ruralidades (CANDIOTTO, 2010).

No Brasil, o interesse pela expansão do turismo rural cresceu significativamente a partir da década de 1990, mas os registros apontam que já na década de 1980 ocorreu deslocamento de pessoas para áreas rurais passando a serem encaradas de forma profissional quando propriedades no Espírito Santo, Santa Catarina e Rio Grande do Sul, devido a dificuldades no setor agropecuário, resolveram diversificar suas atividades e passaram a receber turistas (BRASIL, 2004).

Nesse contexto do desenvolvimento histórico das atividades de agroturismo e turismo rural nas propriedades rurais, se faz necessário o entendimento e características dessas atividades.

Desse modo, entende-se turismo no espaço rural a ação que pode inserir o turismo rural. As muitas práticas turísticas realizadas no espaço rural não são, necessariamente, turismo rural, e sim atividades de lazer, esportivas, ou ócio de citadinos, que ocorrem alheias ao meio em que estão inseridas. Assim, compreende-se turismo em espaço rural ou em áreas rurais também aquelas atividades de lazer realizadas no meio rural, denominadas de turismo ecológico ou ecoturismo, agroturismo, turismo de negócios, turismo de saúde, etc. (SILVA; VILARINHO; DALE, 1998).

Talvez o termo mais conhecido e utilizado entre as pessoas e a mídia neste meio seja o Turismo Rural, o qual apresenta em seu aprofundamento características que há específica.

Através das diretrizes do desenvolvimento do turismo rural juntamente com o auxílio de parceiros e a área acadêmica de todo país que, baseados em aspectos que se referem ao turismo, ao território, à base econômica, aos recursos naturais e culturais e a sociedade, tem-se a conceituação e definese turismo rural como:

[...] o conjunto de atividades turísticas desenvolvidas no meio rural, comprometido com a produção agropecuária, agregando valor a produtos e serviços, resgatando e promovendo o patrimônio cultural e natural da comunidade (BRASIL, 2004, p. 11).

Seguindo a orientação das diretrizes e dos princípios que regem o turismo rural, tem-se as seguintes características: 0 atendimento familiar, ocorre a preservação das raízes, existe uma harmonia e sustentabilidade ambiental, possui autenticidade de identidade, prima-se pela qualidade do produto e ocorre o envolvimento da comunidade local (ROQUE; VIVAN, 2011).

Além dos conceitos sobre turismo no espaço rural e turismo rural, o conceito de agroturismo também se apresenta como parte importante dessa compreensão. 
"De forma geral, entendemos que o agroturismo apresenta todos os atributos do turismo rural, sobretudo pelo fato de ser uma atividade realizada no espaço rural, e ter como principais atrativos as atividades agropecuárias, os produtos agrícolas e o modo de vida rural. Ocorre, porém, que o diferencial do agroturismo em relação ao turismo rural, diz respeito a participação direta e/ou indireta do turista em atividades comuns dos agricultores, como plantio, colheita, ordenha, entre outras. Nesse sentido, toda oferta de agroturismo poderia ser classificada como turismo rural, porém nem toda oferta de turismo rural pressupõe a existência do agroturismo" (CANDIOTTO, 2010, p. 13).

Percebe-se então a diferença entre os conceitos de turismo rural e agroturismo no qual o segundo se caracteriza pela participação direta do turista nas atividades de trabalho desenvolvida na propriedade, fazendo parte do processo social e interação com as demais atividades em que o turista/visitante "mergulha" numa experiência de realmente vivenciar aquelas atividades tradicionais da vida no campo.

Para tratar de forma mais completa e registrar uma modalidade que também está inserida no espaço, temos o conceito de turismo rural na agricultura familiar - TRAF, definido em lei pelo estado do Paraná como:

todas as atividades turísticas que ocorrem na unidade de produção dos agricultores familiares que mantêm as atividades econômicas típicas da agricultura familiar, dispostos a valorizar, respeitar e compartilhar seu modo de vida, o patrimônio cultural e natural, ofertando produtos e serviços de qualidade e proporcionando bem estar aos envolvidos (PARANÁ, 2006, p. 1).

O TRAF, dentro dos conceitos apresentados, seria mais um modelo dentro do turismo rural com algumas características que o diferencia, sendo os requisitos para isso não possuir mais que 4 módulos fiscais (50 hectares); que utilize predominantemente mão de obra da própria família nas atividades econômicas do seu estabelecimento ou empreendimento; que tenha renda familiar predominantemente originada de atividades econômicas vinculadas ao próprio estabelecimento ou empreendimento; e que dirija seu estabelecimento ou empreendimento com sua própria família (PARANÁ, 2006).

Diante dos conceitos apresentados, vê-se a relação que cada um tem com o turismo no espaço rural e suas características, interação com este meio e com o turista. Será tratado de maneira geral todas as atividades desenvolvidas e, para a presente pesquisa, vamos adotar 0 termo Agroturismo. 


\section{Lazer}

Para Marcellino (1996), a concepção de lazer deve estar enraizada nos valores capazes de propiciar o descanso, o divertimento e o desenvolvimento individual e social, que associa essas ações humanas, marcadas pela livre adesão e o prazer, a um entendimento de cultura em seu sentido ampliado.

Conforme Dumazedier (1976), o lazer é um conjunto de ocupações no qual o indivíduo se entrega de livre vontade, seja para repousar, divertir-se, recrear-se, ou para desenvolver sua informação enquanto formação desinteressada. As práticas de lazer acontecem após desembaraçar-se das obrigações profissionais, familiares e sociais, portanto são voluntárias e livres; nelas o homem exerce sua capacidade criadora.

Precisamos entender o lazer como a possibilidade de

produção de cultura, como elemento integrador do exercício da cidadania, como campo privilegiado para manifestação do elemento lúdico, da liberdade e do prazer, e também, como forte instrumento de mudanças pessoal e social, seja qual for a concepção que mais nos identifiquemos e adotemos (lazer relacionado ao tempo, à atitude, ao espaço, ao estado de espírito, etc.) (MARCELLINO, 1997 apud MARINHO, 2004).

A rotina extenuante de trabalho principalmente nos grandes centros urbanos, faz com que as pessoas busquem uma forma de lazer para liberação do estresse do trabalho ou de outros locais de sua vivência que podem até levar a casos patológicos.

De fato, a observação da prática do lazer na sociedade moderna é marcada por fortes componentes de produtividade. Valoriza-se a 'performance', o produto e não o processo de vivência que lhe dá origem; estimula-se a prática compulsória de atividades denotadoras de moda ou 'status'. Além disso, o caráter social requerido pela produtividade confina e adia 0 prazer do expediente, fins de semana, períodos de férias, ou, mais drasticamente, para a aposentadoria (MARCELLINO, 1998, p. 28).

Conforme o comentário de Marcellino (1998), não só vemos mas vivemos essa acelerada forma na busca pela performance e produtividade, muitas vezes esquecendo de cuidar e dar a devida atenção à nossa saúde, que pode ser abalada com os exageros.

Além da utilização do lazer como forma de cuidados com a saúde e fuga da vida agitada combatendo o stress, aqui temos no comentário de Magnani (1988) um dos pontos que reflete a essência à que este trabalho se refere. A relação das pessoas com o meio rural através do lazer pode representar um fator de mudança no seu entendimento sobre esse local e as 
pessoas que lá estão, como também sua forma de ver e entender o que representa para o desenvolvimento da sustentabilidade.

Em muitas vezes não é o novo ou a grande revolução tecnológica que vão trazer mudanças na vida das pessoas, mas o que já existe há muito tempo, o simples, as relações entre as pessoas e o contato com a natureza que sempre promoveu grandes transformações até hoje.

É nesse contexto que o lazer e a recreação estão inseridos para, junto do desenvolvimento rural sustentável, promover mudanças positivas. O direito e a liberdade na busca do lazer em seu tempo livre, oferece um grande número de opções das mais variadas formas. Como o próprio conceito de lazer atribui, é a atitude das pessoas juntamente com a sua bagagem intelectual que levará a direcioná-la para esta ou aquela opção.

\section{A Importância do Agroturismo e Lazer para o Desenvolvimento Rural Sustentável}

$\mathrm{Na}$ atualidade, percebe-se as instabilidades que o setor rural esta passando e a necessidade de haver meios que o auxiliem mantendo suas estruturas físicas e principalmente humanas em harmonia e evolução.

Vemos a comunidade mundial reunindo-se para pensar e discutir estratégias para o momento de degradação ambiental e também a melhoria do bem-estar social das pessoas. Ao mesmo tempo, os modelos de agroturismo aplicados nas propriedades já mostram um caminho diferenciado ajudando nessa reflexão sobre o cuidar e preservar do meio ambiente que nem sempre são vistos como vantagens econômicas pelos sistemas econômicos regentes atualmente.

O início do agroturismo no Brasil na década de 1980, realizado em áreas rurais tende a ser uma nova opção a ser explorada, pois mantém agricultores em seu ambiente de forma rentável e saudável, possibilita uma preservação em ambientes naturais e culturais, gera novos empregos e desenvolve uma localidade (FRANCISCO JUNIOR, 1999).

Concernente à pesquisa, considera-se que este cenário se universaliza e alcança diferentes regiões no mundo. Na realidade do oeste do Paraná, constituído essencialmente por agricultura familiar, também surgiram nos últimos anos experiências de agroturismo e lazer.

Tais atividades têm colaborado para um crescente acesso a serviços de urbanização do meio rural (como moradia, turismo, lazer e outros serviços) e a preservação do meio ambiente. Junto a isso, a proliferação de sítios de recreio (chácaras) tem aumentado, destinadas ao lazer de famílias urbanas, mas também combinando com alguma atividade produtiva agropecuária ou não, do seu morador geralmente chamado de caseiro (SILVA, 1999).

Muitas dessas chácaras de recreio apresentam atividades produtivas de valor comercial considerável, ultrapassando até mesmo a ideia corrente de 'abater parte das despesas da sua 
manutenção' [...] Eles se dedicam principalmente a criação de abelhas, peixes, aves e outros pequenos animais, produção de flores e plantas ornamentais, frutas e hortaliças, atividades de recreação e turismo (pesque pague, hotel fazenda, pousadas, restaurantes, spas) (SILVA, 1999, p. 58).

Outro importante fator e totalmente ligado ao agroturismo e lazer é a educação ambiental dentro do processo de desenvolvimento sustentável do meio rural.

A educação ambiental tem como papel integrar uma verdadeira educação econômica: não se trata de "gestão do meio ambiente", antes, porém, da "gestão" das nossas próprias condutas individuais e coletivas com relação aos recursos vitais extraídos do meio (SAUVÉ, 2005).

A utilização de recursos naturais necessita ser compreendida como também o uso das propriedades e locais para projetos de agroturismo e turismo de forma geral.

O turismo deve incorpora-se a processos integrais de desenvolvimento sustentável dos povos baseados na preservação de suas riquezas naturais e de suas tradições culturais (LEFF, 2010).

Assim, o agroturismo e lazer juntamente com a educação ambiental tem condições de serem ferramentas importantes dentro do desenvolvimento sustentável.

\section{Experiências de Agroturismo e Lazer no Município de Marechal Cândido Rondon (PR)}

O município conta com a maior parte de sua geração econômica baseada na produção agrícola e agropecuária. Com isso, o número de propriedades rurais é grande e algumas dessas propriedades passaram a algum tempo a explorar outras alternativas não-agrícolas em suas estruturas.

Atualmente 5(cinco) propriedades contam com projetos de agroturismo no município.

\section{Sitio das Orquídeas}

O Sítio das Orquídeas é uma propriedade localizada na Linha Bandeirantes no distrito de Novo Três Passos em Marechal Cândido Rondon Pr. Está situada a uma distância de $15 \mathrm{Km}$ do centro da cidade. Com parte da estrada asfaltada, parte coberta com paralelepípedos e outra parte cascalhada. Em relação a estrutura física na propriedade a mesma possui a casa da família (alvenaria), a casa da "nona" (alvenaria), um galpão para guardar os maquinários (alvenaria), uma construção com cozinha industrial para a produção de bolachas e demais produtos uma ampla área aberta para receber os visitantes, uma sala fechada para servir em forma de buffet e no segundo piso uma sala com escritório (alvenaria). Também possui uma cobertura em madeira para produção de orquídeas e outras duas coberturas em estrutura de lona também para a produção de orquídeas. A família é 
composta pela avó, o casal e duas filhas. Na data da pesquisa, uma das filhas estava ajudando na produção, venda de produtos e atendimento aos cliente/turistas que visitavam a propriedade, e a outra filha está estudando em outra cidade. Atualmente a propriedade conta com 10 funcionários contratados sendo o mais novo(a) com 20 anos de idade e o mais velho(a) com 60 anos. Além da venda direta na propriedade, a família também atende a feira na cidade duas vezes por semana. Para divulgar seus produtos e buscar constante inovação em tecnologia de produção e vendas e um melhor conhecimento, a família participa de 10 Feiras de Exposições por ano, direcionadas para a divulgação e venda de orquídeas.

O empreendimento faz sua divulgação através de um folder e um site na rede de computadores. A seguir reproduziremos um trecho do texto do material de divulgação do site: e na Figura 1, fotos do local.

Produção artesanal e um gostinho do campo. Esses são
ingredientes essenciais na fabricação das bolachas
artesanais. O Sítio das Orquídeas utiliza toda a inspiração da
natureza para criar, com sutileza e tranquilidade, essas
iguarias. Feitas com muito carinho e dedicação, as bolachas
tem um sabor e textura que são de dar água na boca. Não
deixe de experimentar essas delícias do campo. Cultivo de
orquídeas de variadas espécies e de grande beleza, as
orquídeas são as preferidas de muitos. Suas cores, formas e
perfumes são de se apaixonar. O Sítio das Orquídeas oferece
toda essa diversidade e beleza natural (SíTIO DAS
ORQUÍDEAS, 2015).

Através desses veículos de divulgação e redes sociais, a propriedade chega a um grande alcance e em meses com datas especiais como mês das mães e dia internacional da mulher chega a receber grandes grupos de cidades distantes.

Quando da nossa visita, a propriedade estava recebendo um grupo de universitários. A proprietária fez um relato do histórico do local e a experiência empreendedora no setor e na sequência foi degustado um café colonial.

A produção de orquídeas é uma beleza a parte que atrai os visitantes que ficam vislumbrados. As orquídeas ficam em grandes áreas cobertas em bancadas elevadas e vários vasos um ao lado do outro que no momento que estão floridas promovem um grande espetáculo. Com vista a esse cenário da beleza das flores, é colocada uma mesa onde os visitantes podem degustar alimentos produzidos no meio rural como salames, cucas, pães, doces (schimier), bolachas e um delicioso café com leite. Ao final da visita podem adquirir as flores de sua preferência como também os produtos alimentícios. 


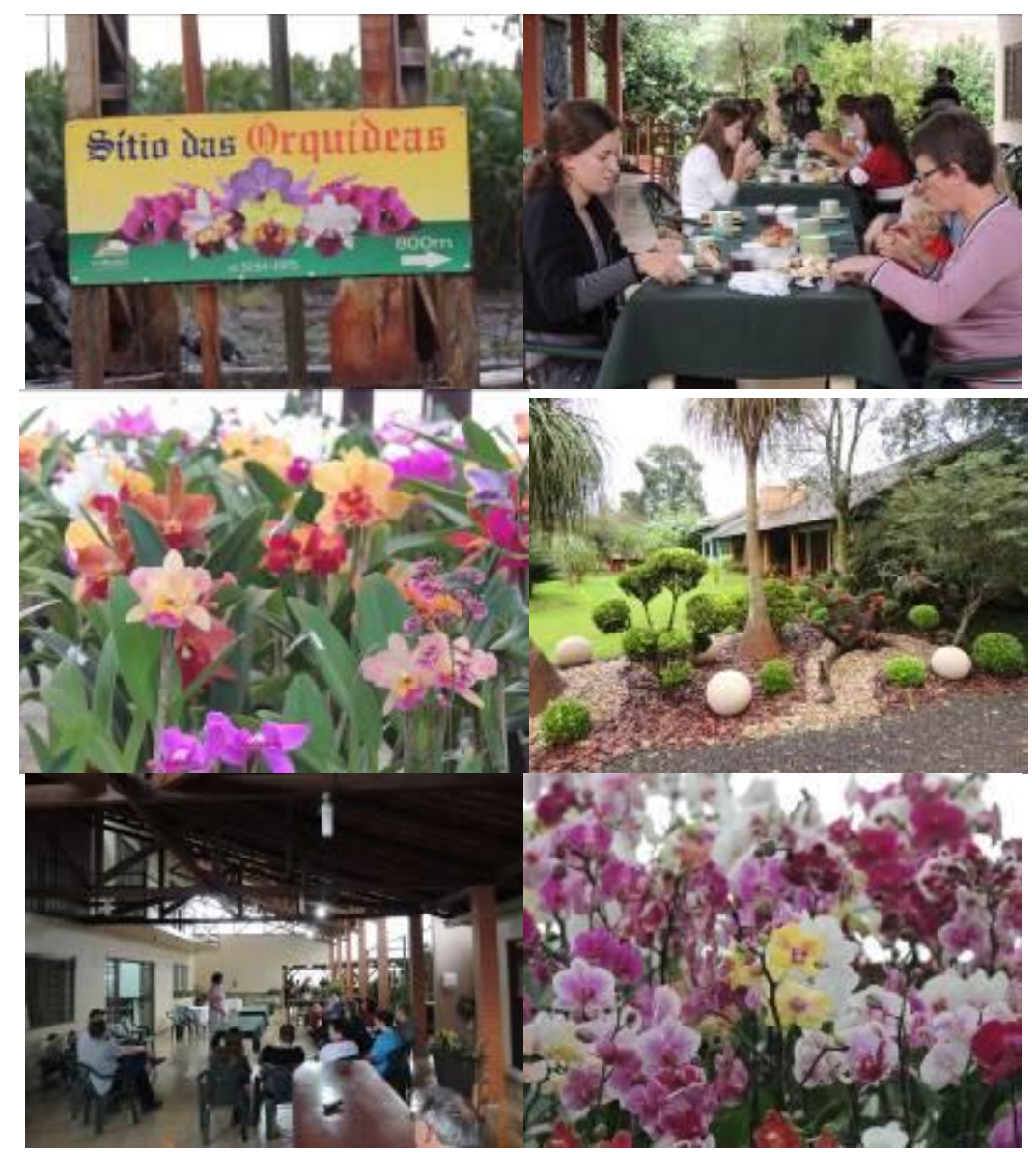

Figura 2: Imagens do Sítio das Orquídias. Fonte: Os autores, 2016.

Figure 2: Site Images of Orchids. Source: The authors, 2016.

\section{Cachoeira da Onça}

Cachoeira da Onça é um empreendimento que se situa em uma propriedade rural localizada na Linha Sanga Cascata distrito de São Roque no município de Marechal Cândido Rondon (PR), a uma distância de 25 $\mathrm{km}$ da sede do município. O acesso é por asfalto e pequena parte de estrada de chão. O atendimento é feito pelo proprietário (58 anos), sua esposa (33 anos) e um funcionário (62 anos) que cuida do local e recebe os visitantes. $O$ local conta com uma casa em madeira onde funciona o restaurante com área coberta e varanda ao redor com estilo rústico e aconchegante. O restaurante possui banheiros no local. As refeições são feitas somente com agendamento. Em outro local da propriedade, existe outra estrutura coberta em alvenaria com estrutura de mesas, churrasqueira e banheiros para locação e uso dos visitantes. Também possui uma pequena casa feita em pedra para a acomodação para pernoite. Em outros locais da área, existem mesas e bancos de concreto e churrasqueiras para os visitantes utilizarem trazendo o alimento para preparo.

Pequenos animais como ovelhas, gansos e outros vivem em cercados específicos. Na área de uso dos visitantes passeiam dois pôneis e um 
jumento muito dóceis que aceitam receber o afago e carinho dos adultos e crianças. Só é necessário esconder bem as sacolas com comida.

Para entrar no local e apenas realizar o passeio até a cachoeira é cobrado uma taxa de $\mathrm{R} \$ 5,00$ por pessoa e se os visitantes quiserem utilizar alguma das edificações citadas acima mais o passeio o valor é $R \$ 10,00$ por pessoa. Crianças abaixo de 10 anos não pagam.

Como principal meio de divulgação encontramos um site do qual destacamos a parte principal; seu objetivo é orientar os visitantes sobre a alimentação no local, as principais atividades, sobre a fauna e a flora existentes na propriedade, e a existência de um templo religioso que faz parte da história do local.

O ideal é chegar ao local antes do almoço, percorrer trilhas com acompanhamento de um guia, que não é extensa, conhecer a queda d'água, ver os pequenos animais que ali habitam, entre alguns deles estão, os macacos, faisões, galizes, quatis, gralhas, ovelhas, gansos, também andar a cavalo e, depois, apreciar a deliciosa comida caseira do interior, desfrutando da paisagem natural do Vale da Onça. $\mathrm{Na}$ propriedade possui cabanas e pousada. Visita a Igreja do Padroeiro São Roque. Venha passar momentos agradáveis em meio a natureza (GIACOBBO TURISMO, 2015).

Entre todas propriedades esta é a que mais contém área verde preservada e a queda d'água é uma das principais atrações do local.

A Figura 2 ilustra a logomarca e apresenta uma imagem da atração que dá nome ao empreendimento, a cachoeira da onça.

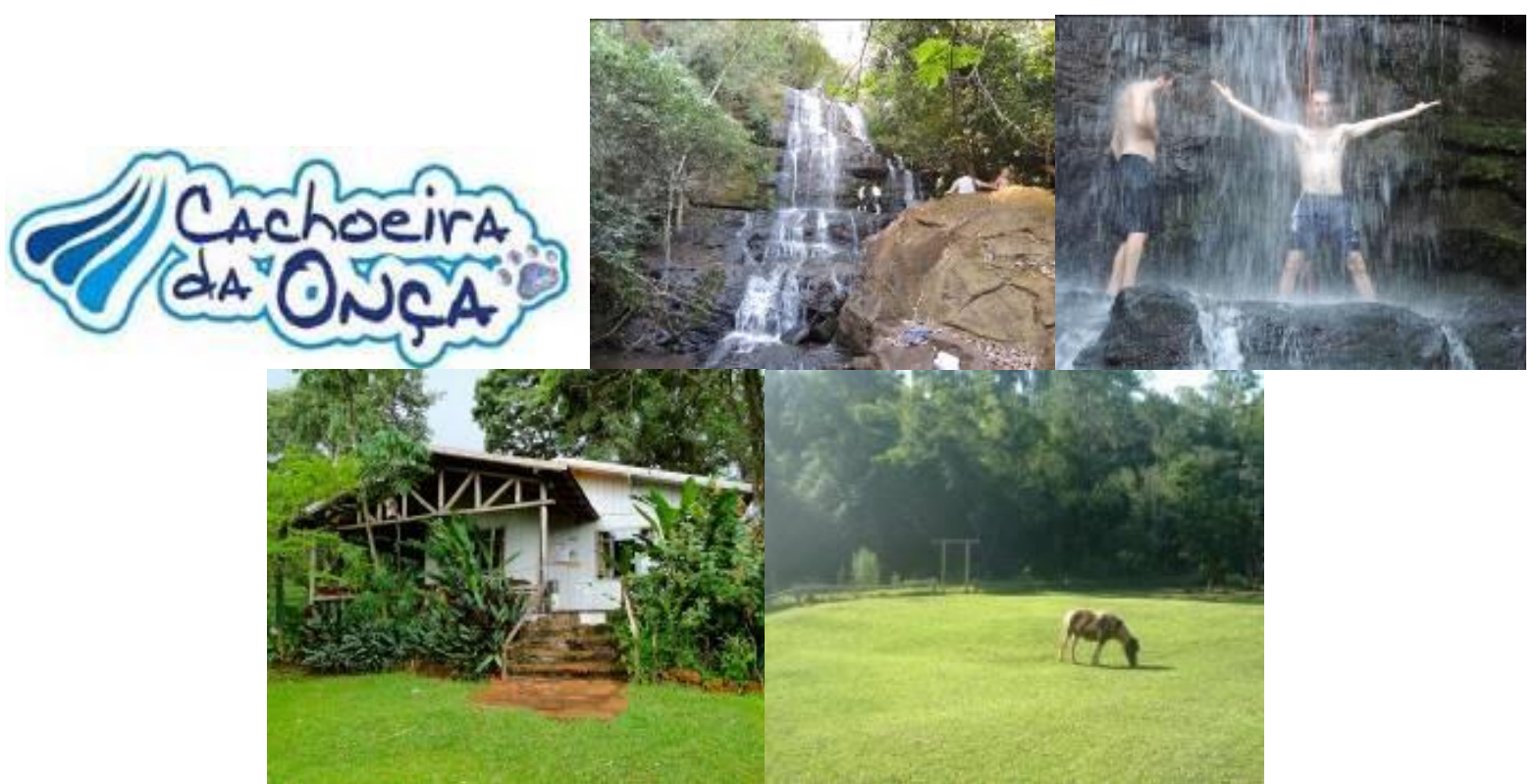

Figura 2: Logomarca e imagens da cachoeira e edificações. Fonte: Os autores, 2016. Figure 2: logo and pictures of the waterfall and buildings. Source: The authors, 2016. 


\section{Pesque Pague do Alli}

Propriedade rural localizada na rodovia PR 491, na Esquina Guaíra, próximo ao aeroporto municipal. Está situada a uma distância de $7 \mathrm{Km}$ do centro da cidade. $O$ acesso é por asfalto e uma parte pequena de estrada de chão. A propriedade é atendida pelo proprietário de 61 anos e 10 contratados (época temporada).

O local conta com vários tanques e diversos tipos de peixes para serem pescados pelos visitantes. Ao redor dos tanques existem bancos de concreto para acomodar os pescadores. As varas para pesca e iscas são oferecidas pelo local.

Outro atrativo é a piscina com um tobogã de 10 metros de altura. Atração que pode ser desfrutada cumprindo as exigências médicas de uso. Se alguém quiser aproveitar por mais de um dia o local, existem chalés para acomodar os visitantes que queiram pernoitar.

Para as refeições o local conta com a estrutura de um restaurante amplo e coberto que comporta em torno de 120 pessoas. Servindo um cardápio variado a base de peixes e acompanhamentos, as pessoas podem saborear, admirando uma vista gostosa do local. Para pessoas que preferem ir até o local e preparar sua refeição, existem um bosque com estrutura de mesas e churrasqueiras.

Abaixo segue um trecho do texto do material de divulgação no site.

O Pesque Pague, Piscina e Lazer Alli, garante diversos atrativos tais como: pesqueiro, restaurante, bosque, piscina, chalés e amplo espaço de lazer para toda família. Durante o dia a infraestrutura disponibiliza ainda área para lazer composta de quadra de vôlei de areia, campo de futebol suíço, cesta de basquete, parquinho infantil e diversos locais para ficar em contato com a natureza. O final da tarde reserva o esplendor dos últimos raios de sol e a revoar das garças. Pesque Pague e Lazer Alli, um ambiente completo que harmoniza com o meio ambiente (ALLI LAZER, 2015).

O pesque pague do Alli é uma das propriedades mais antigas com 25 anos de atuação no setor. O local leva o nome do Avó (in memorian) e hoje é administrado pelo filho e neto.

As instalações divulgadas acima são mantidas em condições de uso, oferecendo boas condições de estadia.

A logomarca que representa a principal atração do local juntamente com a imagem de uma visão geral do pesqueiro esta reproduzida na Figura 3. 


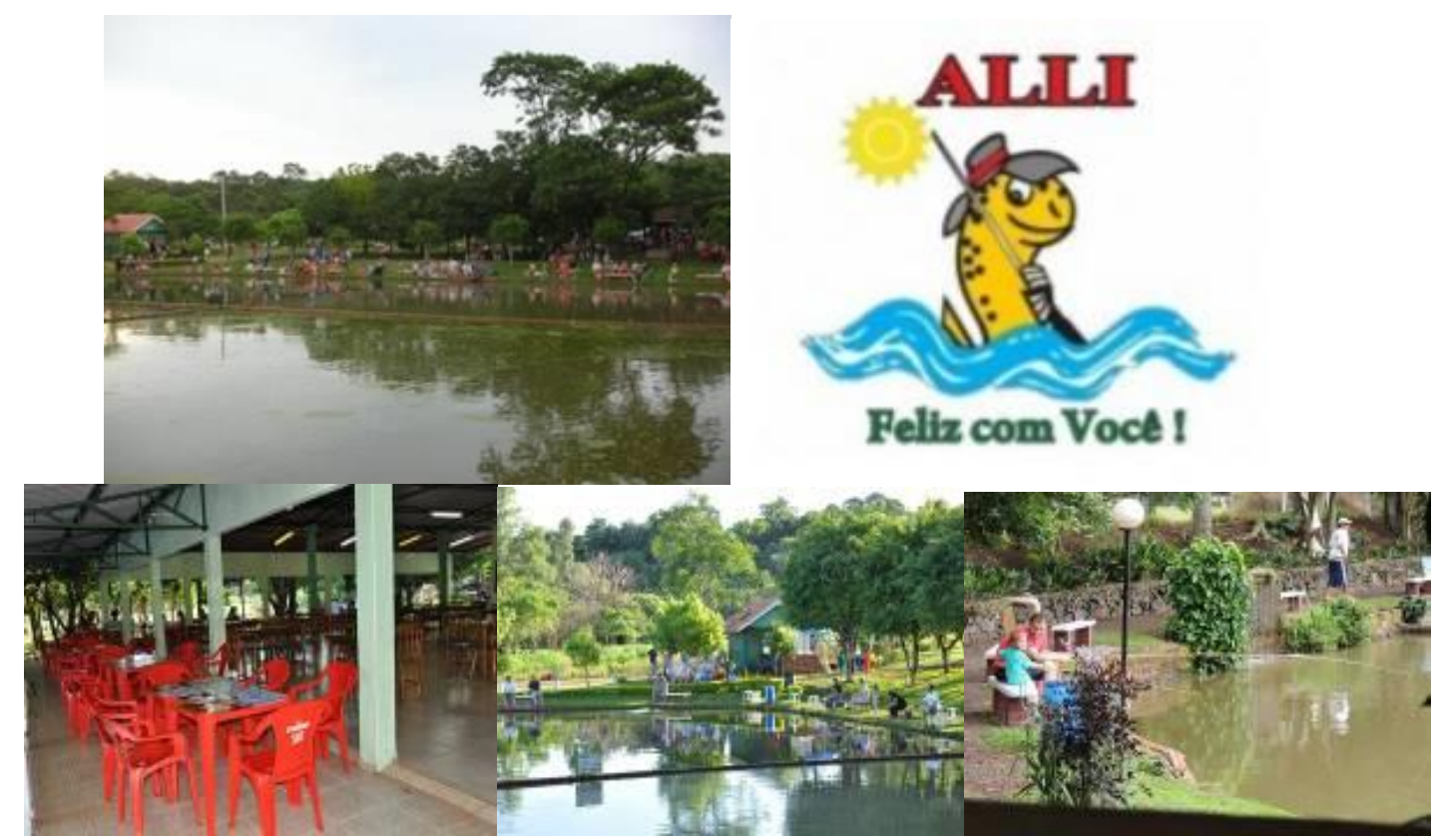

Figura 3: Logomarca, pesqueiros e restaurante. Fonte: Os autores, 2016.

Figure 3: logo, fishing and restaurant. Source: The authors, 2016.

$\mathrm{Na}$ foto acima, três grandes pesqueiros permitem uma grande quantidade de pessoas utilizarem seus arredores com fácil acesso, e ao fundo mais a direita no canto superior aparece o restaurante panorâmico.

\section{Pesque Pague Paulista}

O Pesque Pague Paulista é uma propriedade rural localizada na Esquina Bandeirantes, no distrito de Novo Três Passos no município de Marechal Cândido Rondon (PR). Localiza-se a $12 \mathrm{Km}$ do centro da cidade. $\mathrm{O}$ acesso até o local é pelo asfalto, uma parte de paralelepípedo e uma pequena parte estrada de chão. O atendimento é feito por um casal, ele com 65 anos e ela com 59 anos, e seus filhos que trabalham na cidade e ajudam nos finais de semana (filho 28 anos, filha 26 anos). Dos 16,94 ha que perfaz a propriedade, 7,55 ha, são ocupados pela área do pesqueiro com um total de 18 tanques, incluindo também as edificações. No restante da propriedade é feito o plantio de milho/soja administrado pelos proprietários. No local, além da casa para moradia, existe uma estrutura coberta para o restaurante com uma parte fechada e também com ampla área de varanda, toda em alvenaria. Para refeições ao ar livre, existe um bosque com estrutura de mesas e churrasqueiras. Os visitantes podem trazer seu alimento (menos a bebida) para preparo no local ou adquirir no restaurante. 


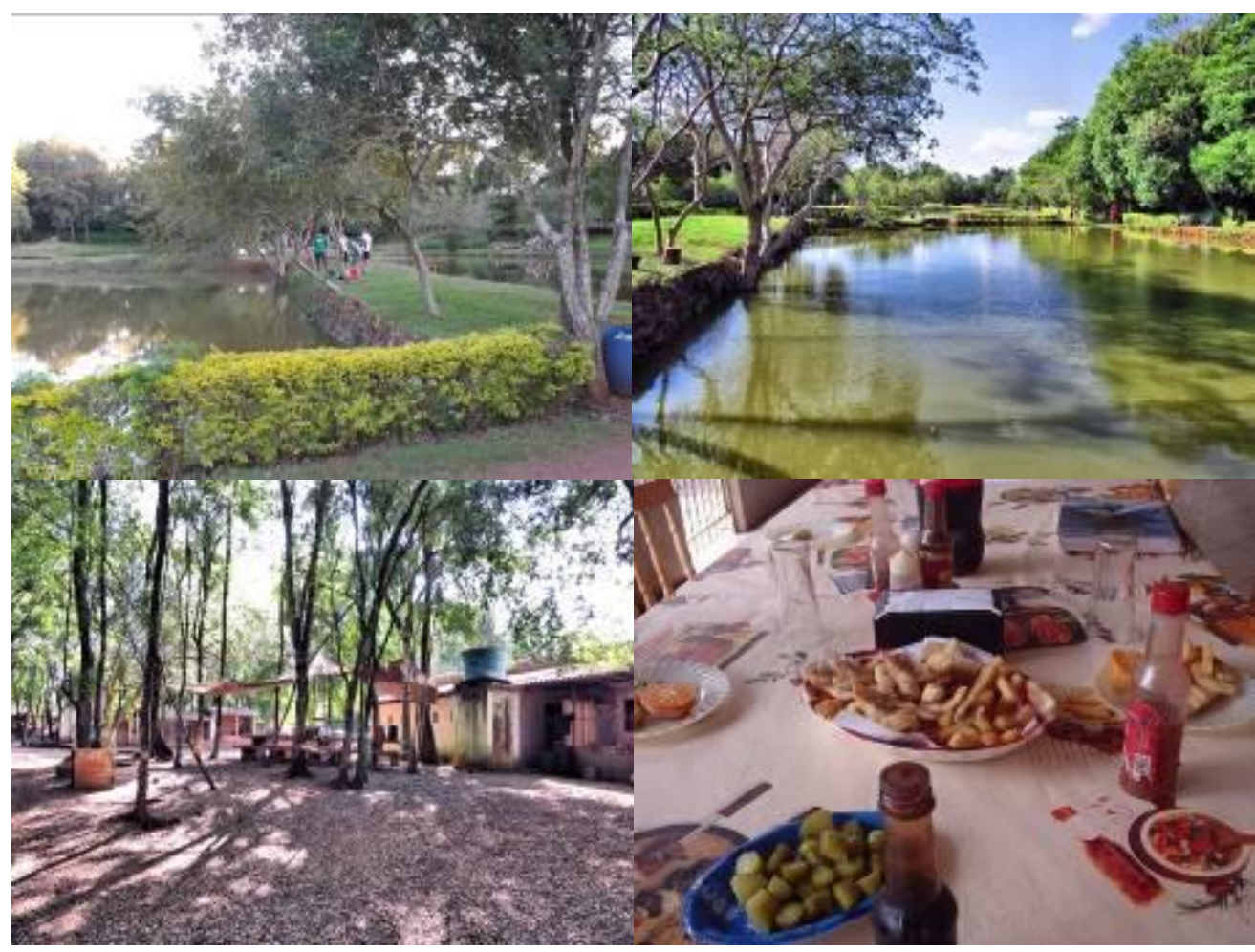

Figura 4: Pesqueiros, camping e restaurante. Fonte: Os autores, 2016.

Figure 4: Fisheries, camping and restaurant. Source: The authors, 2016.

Junto ao restaurante a estrutura de banheiros está disponível também com toda estrutura básica e também com chuveiros.

Conforme a foto acima, os pesqueiros possuem bancos ao seu redor para a comodidade dos visitantes e com boa área arborizada. O local permite fazer passeio para ver pequenos animais como galinhas, patos, gansos, vacas, cavalos, e também deslocando um pequeno trecho, as pessoas podem chegar ao rio Guaçu que passa dentro da propriedade.

\section{Ricas Trilhas Verdes}

Localizada com sua base ladeado ao rio São Francisco no distrito de São Roque - Marechal cândido Rondon (PR), dentro da propriedade da Fazenda Eldorado que possui produção de grãos, gado e aves e sede uma parte do seu espaço com as edificações e o que a área verde oferece para a realização das atividades. A propriedade está a uma distância de $35 \mathrm{Km}$ do centro da cidade. $O$ acesso até o local é parte asfaltado e parte estrada de chão. Ricas Trilhas Verdes é um empreendimento que surgiu há 10 anos e tem como objetivo a realização de atividades de aventura na natureza. $O$ responsável das atividades da Ricas Trilhas Verdes é feito pelo responsável que possui 52 anos de idade e sua equipe composta de 9 pessoas. As atividades de aventura na natureza realizadas no local são: trilhas ecológicas e contemplativas, tirolesa, arvorismo, rapel, rafting, e expedição para empresários. Tem como foco oferecer atividades de lazer e de aventuras 
como também realizar treinamentos específicos para grupos diversos como empresas, prefeituras, escolas, batalhões de polícia, etc.

No local existe um barracão que serve como armazenamento de materiais e também é usado para a realização de atividades e palestras quando necessário. Conta também com outra construção que serve como casa de hospedagem da equipe de trabalho com banheiros para uso da equipe e visitantes. A casa possui uma cozinha externa para quem quiser preparar refeições no local e uma ampla varanda. Não possui restaurante. Existe uma área para camping com grande gramado (Figura 5).

A equipe conta com diversos profissionais como psicóloga, agrônomos e educador físico. Realiza palestras e orientações com foco na educação ambiental e orientações relacionadas a sustentabilidade e saúde.

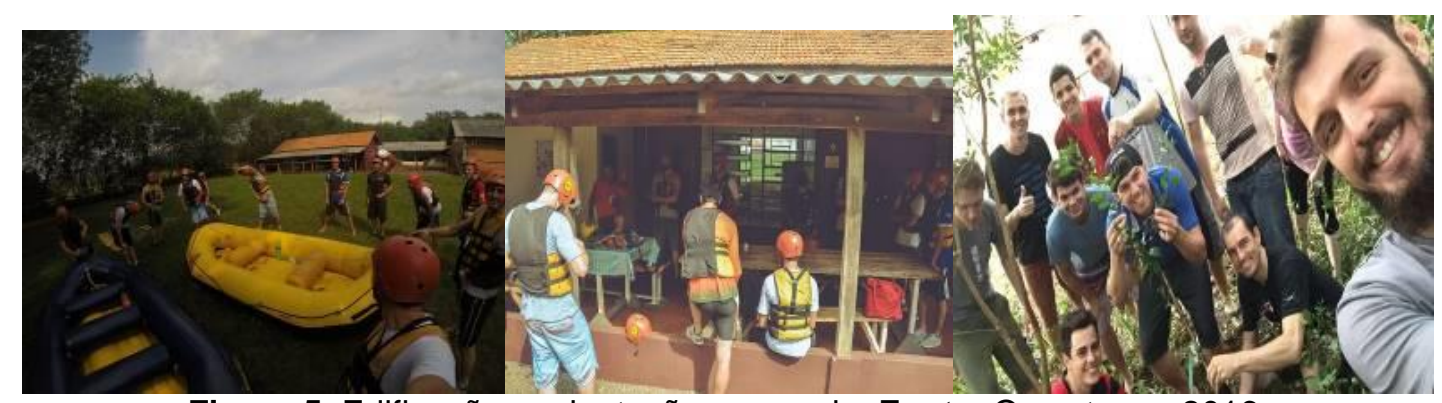

Figura 5: Edificações, orientação e passeio. Fonte: Os autores, 2016.

Figure 5: Buildings, orientation and tour. Source: The authors, 2016.

A união de uma propriedade cruzada por um rio e o gosto pela aventura formam o ambiente ideal para quem quer unir adrenalina com a contemplação da natureza. Com essa ideia, o produtor rural abre as portas de sua propriedade para aproveitar outras formas de utilização através do agroturismo agregando valor ao local, juntamente com criação de novas frentes de trabalho tanto de mão de obra especializada como mão de obra local.

\section{Considerações finais}

Dentro de todo o esse contexto onde propriedades rurais com produções agrícolas tradicionais em dado momento veem a necessidade de incorporar outras atividades não agrícolas, principalmente pelo fato do ganho econômico, constata que alguns modelos de medidas e custos de produção elevado para o setor, não servem para todos.

No presente trabalho, constata-se que economicamente os projetos de agroturismo e lazer trouxeram um aumento da renda, se tornando a atividade principal de arrecadação da propriedade. A insegurança devido as incertezas do clima juntamente com as dificuldades de alto custo de produção das atividade agrícolas tradicionais, faz um produtor comentar que "se na produção não der, eu me escoro nas flores" (as flores são a produção incorporada na propriedade que faz parte do projeto de agroturismo).

Ficou constatado na pesquisa a evolução física das propriedades, as quais conseguiram, na maioria dos casos, investir no seu desenvolvimento 
com recursos próprios. Foram feitas edificações realizadas para os melhoramentos necessários com recursos advindos do agroturismo, contribuindo também não só para o bem-estar dos visitantes, mas principalmente para a família.

Outro momento importante que foi observado no trabalho é os filhos que junto aos seus pais auxiliam nas atividades não só as tradicionais de produção agrícola, mas principalmente as atividades de agroturismo e lazer, chamam a atenção desses jovens. Vemos um grande problema no meio rural relacionado a sucessão familiar, onde jovens querem sair da propriedade, trabalhar na cidade e seguir outros caminhos diferentes dos pais. Neste estudo, verificou-se os filhos trabalhando com pais nos projetos de agroturismo e atividades tradicionais, saindo para estudar, mas regressando para continuidade dos mesmos.

Os projetos de agroturismo ao longo do tempo foram crescendo e outro fator importante constatado neste estudo é a necessidade de mão de obra devido a este desenvolvimento, abriram-se novas frente de trabalho onde antes não existia. Em uma propriedade, chega ao número de 10 pessoas contratadas para as funções voltadas para atender as necessidades do agroturismo. Vizinhos adultos e jovens das propriedades próximas e até da cidade são contratados com carteira assinada. Vendo esse setor abrindo novas frentes de trabalho com melhor aproveitamento do potencial que tem as propriedades, verifica-se o desenvolvimento de forma sustentável.

Junto a esse desenvolvimento das famílias e as melhoras observadas com os benefícios dos projetos de agroturismo, percebe-se que outras melhoras também acontecem no meio ambiente daquele lugar. A natureza é um dos atrativos principais. Mantê-la e preserva-la é necessário para atrair pessoas para as propriedades. Cuidados com a água de nascentes, as resevas legais e ciliares, como também os animais que estão nesse meio. Apesar de modestos, existem ações nas propriedades que procuram orientar os visitantes sobre educação ambiental, fazendo com que levem adiante este hábito do cuidar e preservar o meio ambiente. Em uma propriedade após a realização da atividade principal de agroturismo, um grupo de jovens realizou o plantio de uma muda de árvore perto do rio. Jovens na faixa dos 20 aos 30 anos, onde alguns ainda não tinham plantado uma árvore. Momento simples, mas carregado de importância e emoção que fica gravado na memória de quem participou.

Assim, dentro da perspectiva do desenvolvimento rural sustentável o agroturismo e lazer estão muito bem inseridos, proporcionando mudanças significativas na vida de moradores e visitantes.

\section{Referências}

ABRAMOVAY, R. Ruralidade e desenvolvimento territorial. Gazeta Mercantil, São Paulo, 15 abr. 2001.

ALLI LAZER. Pesque pague, piscina e lazer. 2015. Disponível em: <http://www.allilazer.com.br/>. Acesso em: 15 set. 2015. 
ALMEIDA, J. Da ideologia do progresso à ideia de desenvolvimento (rural) sustentável. In: ALMEIDA, J.; NAVARRO, Z. (orgs.). Reconstruindo a agricultura: ideias e ideais na perspectiva do desenvolvimento rural sustentável. Porto Alegre: Editora da Universidade, 1997. p. 33-55.

BORDENAVE, J.E.D. O que é comunicação rural. 3. ed. São Paulo: Brasiliense, 1988.

BRASIL. Ministério do Turismo. Diretrizes para o desenvolvimento do turismo rural no Brasil. Brasília, 2004.

CANDIOTTO, L.Z.P. Elementos para o debate acerca do conceito de turismo rural. Revista Turismo em Análise, v. 21, n. 1, p. 3-24, 2010.

CINTRA, H.B. Indicadores de sustentabilidade para o turismo e o turismo rural: uma proposta para Aldeia Velha, município de Silva Jardim-RJ, e região do entorno/Heitor de Brito Cintra. 2004. 127f. Dissertação (Mestrado em Ciência Ambiental) - Universidade Federal Fluminense, Niterói, 2004.

COSTABEBER, J.A.; CAPORAL, F.R. Possibilidades e alternativas do desenvolvimento rural sustentável. In: VELA, H. (Org.) Agricultura familiar e desenvolvimento rural sustentável no Mercosul. Santa Maria: Editora da UFSM; Pallotti, 2003. p. 157-194.

DUMAZEDIER, J. Lazer e cultura popular. São Paulo: Perspectiva, 1976.

FERREIRA, F.L. Análise dos indicadores municipais de sustentabilidade ambiental utilizados no Grande ABC. 2011. 164p. Dissertação (Mestrado em Administração) - Univ. Municipal de São Caetano do Sul, São Caetano do Sul, 2011.

FRANCISCO JÚNIOR, J.C. Processo de desenvolvimento do ecoturismo em Brotas. In: CONGRESSO BRASILEIRO DE TURISMO, 1., 1999, Piracicaba. Anais... Piracicaba: FEALQ, 1999. p.229-233.

GIACOBBO TURISMO. Cachoeira da Onça. 2015. Disponível em: $<$ http://www.giacobbo.com.br/turismo/cidades.php?c=14>. Acesso em: 15 set. 2015.

GUZZATTI, T.C. O agroturismo como instrumento de desenvolvimento rural: sistematização e análise das estratégias utilizadas para a implantação de um programa de agroturismo nas encostas da Serra Geral catarinense. 2003. $168 \mathrm{f}$. Dissertação (Mestrado em Engenharia de Produção) - Universidade Federal de Santa Catarina, Florianópolis, 2003.

KRAMA, M.R. Análise dos indicadores de desenvolvimento sustentável no Brasil, usando a ferramenta painel de sustentabilidade. 2009. $171 \mathrm{f}$.

Dissertação (Mestrado em Engenharia de Produção e Sistemas) - Pontifícia Universidade Católica do Paraná, Curitiba, 2009.

LEFF, E. Discursos sustentáveis. Tradução de Silvana Cobucci Leite. São Paulo: Cortez, 2010.

LIMA, F.A.X.; SOUZA, G.S.C.; MATTOS, J.L.S. Turismo rural e agricultura familiar de base agroecológica: uma experiência no município de Abreu e Lima PE. Revista Monografias Ambientais, v. 10, n. 10, p. 2311-2317, 2013.

MAGNANI, J.G.C. Festa no pedaço: cultura popular e lazer na cidade. Unesp, 1998. 
MARCELLINO, N.C. Estudos do lazer. Campinas: Autores Associados, 1996. MARCELLINO, N.C.Lazer e educação. São Paulo: Papirus, 1998.

MARINHO, A. Atividades na natureza, lazer e educação ambiental: refletindo sobre algumas possibilidades. Motrivivência, n. 22, p. 47-70, 2004.

PARANÁ. Lei n. 15.143, de 31 de maio de 2006. Define as atividades turísticas que especifica, como atividades de "Turismo Rural na Agricultura Familiar". Diário Oficial, Curitiba, 2006.

ROQUE, A.M.; VIVAN, A.M. O turismo no espaço rural: uma estratégia para a nova gestão rural brasileira. Organizações Rurais \& Agroindustriais, v.1, n.1, 2011.

SAUVÉ, L. Educação ambiental: possibilidades e limitações. Educação e Pesquisa, São Paulo, v. 31, n. 2, 2005.

SILVA, J.F.G. O novo rural brasileiro. Campinas: Universidade Estadual de Campinas; Instituto de Economia, 1999.

SCHWARTZ, G.M. Aventuras na natureza: consolidando significados. Jundiaí, SP: Fontoura, 2006.

SCHNEIDER, S.; FIALHO, M.A.V. Atividades não agrícolas e turismo rural no Rio Grande do Sul. In: ALMEIDA, J.A.; RIEDL, M. (Orgs.) Turismo rural: ecologia, lazer e desenvolvimento. Bauru: EDUSC, 2000. p. 15-50.

SIENA, O. Método para avaliar progresso em direção ao desenvolvimento sustentável. 2002. 234p. Tese (Doutorado em Engenharia da Produção) Universidade Federal de Santa Catarina, Florianópolis, 2002.

SILVA; VILARINHO, C.; DALE, P. Turismo em áreas rurais: suas possibilidades e limitações no Brasil. Caderno CRH, v. 11, n. 28, 1998.

SÍTIO DAS ORQUIDEAS. Conheça o Sítio das Orquídeas. 2015. Disponível em: <http://www.sitiodasorquideas.net.br/biscoitos-caseiros.php>. Acesso em: 15 set. 2015.

Cristiano Luis Metzner: Universidade Estadual do Oeste do Paraná, Marechal Candido Rondon, PR, Brasil.

E-mail: suko_cm@hotmail.com

Link para o currículo Lattes: http://lattes.cnpq.br/8451393923926714

Alvori Alhert: Universidade Estadual do Oeste do Paraná, Marechal Candido Rondon, PR, Brasil.

E-mail: alvorialhert@yahoo.com.br

Link para o currículo Lattes: http://lattes.cnpq.br/6070773522751798

Data de submissão: 01 de setembro de 2016

Data de recebimento de correções: 20 de fevereiro de 2018

Data do aceite: 20 de fevereiro de 2018

Avaliado anonimamente 